\title{
DIREITO DA SEGURIDADE SOCIAL, GÊNERO E POBREZA: PRIMEIROS PASSOS DESTA INTERSECÇÃO NA FACULDADE DE DIREITO DA USP
}

\author{
SOCIAL SECURITY LAW, GENDER AND POVERTY: FIRST APPROACHES TOWARD THE \\ INTERSECTION AMONG THEM AT THE UNIVERSITY OF SÃO PAULO LAW SCHOOL
}

\section{Homero Batista Mateus da Silva* Regina Stela Corrêa Vieira**}

\begin{abstract}
Resumo:
O Grupo de Pesquisa Direito da Seguridade Social, Gênero e Pobreza, criado em 2014 na Faculdade de Direito da Universidade de São Paulo, é pioneiro em sua proposta de inserir a perspectiva de gênero nos estudos da Seguridade Social, fundamental para a formação de um olhar sensível às mulheres no contexto jurídico e de elaboração de políticas públicas nessa área. Isso permite abrir espaço para a elaboração de um Direito da Seguridade Social voltado às demandas específicas que as relações desiguais provocam, levando em conta especialmente a realidade e as demandas das mulheres pobres, maiores afetadas na dinâmica da exclusão social. O contexto de surgimento do grupo, as demandas de estudantes e a definição da linha de pesquisa são alvo do presente artigo, cuja finalidade é documentar os primeiros passos desta iniciativa.
\end{abstract}

Palavras-chave: Seguridade Social. Gênero. Pobreza. Grupo de pesquisa. Universidade de São Paulo.

\begin{abstract}
:
The Social Security Law, Gender and Poverty Research Group, created in 2014 at the University of São Paulo Law School, is a pioneer in its proposal to integrate the gender perspective in the social security studies, which is essential to the formation of a sensitive gaze towards women in the legal context and to the shaping of public policies in this area. This allows the development of Social Security Law geared to the specific demands that unequal relationships cause, taking into account especially the reality and demands of poor women, who are the most affected by the dynamics of social exclusion. This article targets the group's emergence context, the demands of students and the definition of the research line, and intents to document the first steps of this initiative.
\end{abstract}

Keywords: Social security. Gender. Poverty. Research group. University of São Paulo.

Professor Doutor do Departamento de Direito do Trabalho e da Seguridade Social da Faculdade de Direito da Universidade de São Paulo; juiz do trabalho titular da $88^{\text {a }}$ Vara do Trabalho de São Paulo; professor orientador do Grupo de Pesquisa "Direito da Seguridade Social, Gênero e Pobreza", atividade de cultura e extensão da FDUSP. www.direito.usp.br/homero.

** Mestra e doutoranda em Direito do Trabalho e da Seguridade Social pela Faculdade de Direito da Universidade de São Paulo; membro do Grupo de Pesquisa "Trabalho e Capital", vinculado à FDUSP; monitora do Grupo de Pesquisa "Direito da Seguridade Social, Gênero e Pobreza", atividade de cultura e extensão da FDUSP. regina.vieira@usp.br. 
1. Introdução

O Direito da Seguridade Social visa a garantir os direitos relativos à Saúde, à Previdência e à Assistência Social, conforme art. 194 e seguintes da Constituição. A previsão da Seguridade Social, trazida pela Carta de 1988, permitiu uma visão integrada destas três frentes de políticas sociais no Brasil, bem como introduziu a perspectiva de Direitos Sociais universais como parte da condição de cidadania. No entanto, restaram grandes obstáculos para a efetivação da Seguridade Social como constitucionalmente formulada, bem como para a realização de uma sinergia verdadeira entre os setores que a compõem. ${ }^{1}$

Reconhecida como direito humano pelos arts. XXII e XXV da Declaração Universal dos Direitos Humanos de 1948, ${ }^{2}$ a Seguridade Social é uma ferramenta essencial no combate à pobreza e garantia de dignidade a todas as pessoas, além de contribuir para o desenvolvimento econômico e a estabilidade social. Seu papel também é reconhecido pela Organização Internacional do Trabalho (OIT), com destaque para a Convenção 102, sobre normas mínimas da Seguridade Social, e para a Recomendação 202, relativa aos pisos de proteção social, que registra em seu preâmbulo a importância na redução da pobreza, da desigualdade, da exclusão social e na promoção de igualdade de oportunidades e igualdade de gênero e de raça. ${ }^{3}$

Na Faculdade de Direito da Universidade de São Paulo, a centralidade da Seguridade Social para a construção de um país mais igualitário e justo não só foi reconhecida pelo corpo docente do então Departamento de Direito do Trabalho, como os professores firmaram posicionamento acerca da necessidade de inserir a disciplina no nome do departamento.

Assim, em reunião do Conselho Departamental de 16 de abril de 2001, foi deliberada a mudança do nome do Departamento de Direito do Trabalho, incluindo-se "e da Seguridade Social", de modo a inserir a disciplina em seu projeto acadêmico, com a justificativa de que "de todos é conhecido que a resposta ao problema da Previdência Social, tanto no setor público, quanto privado, é crucial para a solução das dificuldades vividas pelo Estado moderno", de modo que "a busca de soluções para o modelo

1 MONNERAT, Giselle Lavinas; SOUZA, Rosimary Gonçalves de. Da seguridade social à intersetorialidade: reflexões sobre a integração das políticas sociais no Brasil. Revista Katálysis, Florianópolis, v. 14, n. 1, jan./ jun. 2011.

2 ORGANIZAÇÃO DAS NAÇÕES UNIDAS. Declaração Universal dos Direitos Humanos. Nova Iorque: ONU, 1948. Disponível em: <http://www.dudh.org.br/wp-content/uploads/2014/12/dudh.pdf>. Acesso em: 7 abr. 2015 .

3 ORGANIZAÇÃO INTERNACIONAL DO TRABALHO. Recommendation 202: Social Protection Floors Recommendation. Geneva: ILO, 2012. Disponível em: <http://www.ilo.org/dyn/normlex/en/f?p=NORML EXPUB:12100:0::NO::P12100_INSTRUMENT_ID:3065524> Acesso em: 7 abr. 2015. 
previdenciário (...) interessa de perto à comunidade como um todo". A fundamentação continua, reforçando o caráter simbólico da medida:

O Departamento de Direito do Trabalho foi o primeiro Departamento a ser constituído na Faculdade de Direito. Ainda sob a chefia do saudoso Professor A. F. Cesarino Jr., seu idealizador, denominava-se Direito Social, tendo em vista a importância que representava o novo ramo do Direito para a sociedade. (...) As profundas transformações econômicas impõem as reflexões sugeridas nas linhas de pesquisa, de sorte o Departamento mantenha sua vocação histórica de centro de excelência voltado ao debate das questões econômico-sociais de nosso tempo. Assim, para atuar de forma mais abrangente dentro e fora da comunidade acadêmica, estamos propondo a mudança de nome do Departamento de Direito do Trabalho para Departamento de Direito do Trabalho e da Seguridade Social. A mudança proposta reflete a missão que queremos desempenhar, mantendo o pioneirismo iniciado pelo Prof. Cesarino $\mathrm{Jr}^{4}$

Em 23 de abril 2001, o ofício DTB-0242001/FD/1904 com a solicitação de alteração de nome foi protocolado junto à Diretoria da Faculdade de Direito. Primeiramente, a proposta foi encaminhada para o Conselho Técnico Administrativo (CTA), no qual foi aprovada por unanimidade em 8 de junho de 2001. Em seguida, seguiu para a Congregação da Faculdade de Direito, tendo sido deliberada e aprovada na sessão do dia 28 de junho de $2001 .^{5}$

Em 8 de outubro de 2005, o Diário Oficial do Estado de São Paulo publicou a Resolução USP-5.252, oficializando que “O Departamento de Direito do Trabalho da Faculdade de Direito passa a denominar-se Departamento de Direito do Trabalho e da Seguridade Social" (art. $\left.1^{\circ}\right){ }^{6}$

Apesar do reconhecimento da Seguridade Social como disciplina central para o desenvolvimento do país, este ramo do Direito permaneceu pouco desenvolvido nesta faculdade, o que pode ser exemplificado pelo número de disciplinas credenciadas no Departamento de Direito do Trabalho e da Seguridade Social (DTBS): são apenas seis dedicadas à Seguridade Social (DTB0317, DTB0412, DTB0413, DTB0420, DTB0571,

4 UNIVERSIDADE DE SÃO PAULO. Oficio DTB-0242001/FD/1904. Acervo do Departamento de Direito do Trabalho e da Seguridade Social, 2001.

5 UNIVERSIDADE DE SÃO PAULO. Ata da $154^{a}$ Sessão da Congregação. Acervo da Assistência Acadêmica, 28 jun. 2001.

6 DIÁRIO OFICIAL DO ESTADO DE SÃO PAUlO, Poder Executivo - Seção 1, 8 out. 2015, p. 69. Disponível em: <http://www.imprensaoficial.com.br/PortalIO/DO/BuscaDO2001Documento_11_4. aspx?link=/2005/executivo\%2520secao\%2520i/outubro/08/pag_0069_47S5K48D78MHJe2LUG18H3IVP PH.pdf\&pagina $=69 \&$ data $=08 / 10 / 2005 \&$ caderno $=$ Executivo $\% 20 I \&$ paginaordenacao $=10069>$. Acesso em: 25 abr. 2015. 
DTB0572), em face de 31 disciplinas dedicadas à outra especialidade do departamento, o Direito do Trabalho. ${ }^{7}$

$\mathrm{O}$ desestímulo à pesquisa neste ramo do Direito também é refletido nas defesas de teses de doutorado e dissertações de mestrado: no período de 2000 a 2014, foram produzidas nesta faculdade 21 monografias cujo assunto preponderante era Seguridade Social. Interessante notar que seis destes trabalhos não foram apresentados ao Departamento de Trabalho e da Seguridade Social, mas sim aos Departamentos de Direito Econômico, Financeiro e Tributário (DEF), de Direito do Estado (DES), de Direito Internacional e Comparado (DIN) e de Direito Processual (DPC). ${ }^{8}$

A falta de interesse dos graduandos e graduandas sobre o tema também é sintoma de que a disciplina merece mais atenção. De acordo os registros cordialmente fornecidos pela Secretaria de Graduação (Seção de Alunos), são poucos estudantes quintanistas que vinculam sua tese de láurea, apresentada para conclusão da graduação, ao Departamento de Direito do Trabalho e da Seguridade Social, dentre as quais a maioria dedica-se ao Direito do Trabalho, deixando de lado a Seguridade Social: em 2009, das 436 teses de láurea registradas, 18 eram vinculadas ao DTBS, das quais nenhuma tratava de seguridade; em 2010, foram 448 teses de láurea, sendo 12 no DTBS, das quais nenhuma sobre seguridade; do mesmo modo, em 2011, das 420 teses de láurea registradas, 29 estavam no DTBS, mas nenhuma tratava da seguridade.

Houve um pequeno avanço em 2013, ano em que, dentre as 434 teses apresentadas na faculdade, 44 estavam vinculadas ao DTBS, três das quais se debruçaram sobre a Seguridade Social. Em 2014, das 406 teses catalogadas, 33 vincularam-se ao DTBS, sendo que apenas uma destas voltou-se à temática, tratando da desaposentação.

Acreditamos que a mudança efetiva desse quadro somente é possível se retomarmos o projeto departamental de 2001 de incentivo à pesquisa, por meio de novas abordagens da disciplina em sala de aula e da formação de grupos de estudo sobre Seguridade Social sob os mais diversos pontos de vista, com a finalidade de pensar nos meios como o Direito pode servir para o aperfeiçoamento do modelo constitucional e apara a garantia dos Direitos Sociais a toda a população.

É essa a proposta do Grupo de Pesquisa Direito da Seguridade Social, Gênero e Pobreza, fundado em 2014, vinculado ao Departamento de Direito do Trabalho e da Seguridade Social da Faculdade de Direito, objeto do presente artigo. De antemão, vemos que o grupo de pesquisa já atraiu interesse sobre o tema, vez que das cinco teses de

7 Catálogo de disciplinas de graduação da USP. Disponível em: < https://uspdigital.usp.br/jupiterweb/>. Acesso em: 14 abr. 2015.

8 Pesquisa por meio do sistema Dedalus das bibliotecas da Universidade de São Paulo. Disponível em: $<$ http://dedalus.usp.br/F?RN=572747624>. Acesso em: 07 abr. 2015. 
láurea orientadas pelo Professor Homero Batista Mateus da Silva, em 2015, três abordam temas de Seguridade Social.

2. Surgimento do grupo e definição da linha de pesquisa

Na estrutura curricular da graduação na Faculdade de Direito da USP, figura como obrigatória a estudantes do terceiro ano ( $6^{\circ}$ semestre $)$ a disciplina "Seguridade Social" (DTB0317), vinculada ao Departamento de Direito do Trabalho e da Seguridade Social.

Em 2013, a partir da proposta metodológica de apresentar aos alunos e alunas todo o tripé da Seguridade Social - Previdência, Assistência e Saúde -, trazendo à sala de aula exemplos e questões atuais envolvendo a matéria, que fazem parte da realidade dos estudantes ou estão em debate na cena política e econômica do país, e buscando evitar as enfoques restritos ao debate sobre fontes de custeio e benefícios, a mudança de perspectiva despertou o interesse acadêmico. Temas como a aposentadoria em idades e tempos de contribuição diferentes para homens e mulheres, a adaptação da legislação previdenciária a famílias homoafetivas e os programas sociais voltados às mulheres foram alguns dos que mais chamaram a atenção das turmas.

Por conta do interesse crescente de estudantes em se aprofundar em muito do que era problematizado em aula, em reunião da pós-graduação decidimos estruturar um grupo que envolvesse alunas e alunos interessados em pesquisar temáticas de Seguridade Social com pontos de partida conscientes das relações de poder econômicas, étnicas e entre os sexos que integram nossa sociedade.

Assim, a definição da linha de pesquisa do grupo teve como base a perspectiva interseccional entre gênero, raça e classe, ${ }^{9}$ o que nos levou ao fenômeno da feminização da pobreza, colocado em evidência na IV Conferência Mundial sobre as Mulheres (Pequim, 1995), cuja Declaração constata a persistência das desigualdades de gênero, situação "exacerbada pela crescente pobreza que afeta a vida da maioria da população mundial, em especial a das mulheres e crianças”. Ademais, sua Plataforma de

Sobre o tema, ver: KERGOAT, Danièle. Dinâmica e consubstancialidade das relações sociais. Novos Estudos: CEBRAP, n. 86, p. 93-103, 2010. Disponível em: <http://novosestudos.uol.com.br/v1/files/uploads/ contents/146/20100407_06_NEC86_kergoat_p92a103.pdf>; e KERNER, Ina. Tudo é interseccional? Sobre a relação entre racismo e sexismo. Novos Estudos: CEBRAP, n. 93, p. 45-58, 2012. Disponível em: <http:// novosestudos.uol.com.br/v1/files/uploads/contents/content_25/file_25.pdf>. 
Ação destaca que "a pobreza tem aumentado em termos absolutos e relativos, e o número de mulheres pobres tem aumentado na maioria das regiões". ${ }^{10 / 11}$

No Brasil, de acordo com o Relatório Anual Socioeconômico da Mulher de 2013, a comparação da situação de pobreza por sexo e raça mostra "níveis de pobreza muito elevados entre a população negra em geral, com piores níveis entre as mulheres negras": são aproximadamente 55 milhões de pobres no país, dentre os quais 37 milhões de pessoas negras. Segundo dados do relatório, 39,8\% das mulheres negras estão em situação de pobreza, em comparação a 38,1\% dos homens negros, 20,3\% das mulheres brancas e $19,5 \%$ entre os homens brancos. Ademais, as famílias chefiadas por mulheres com filhos ou filhas "tendem a apresentar maiores índices de pobreza". ${ }^{12}$

Despertadas por esta realidade, as seguintes perguntas passaram a ser fio condutor para os estudos do grupo: quais as ações do Estado para combater a situação de pobreza das mulheres no Brasil? Elas têm sido efetivas no combate à pobreza das mulheres e de suas famílias? Como o Direito da Seguridade Social pode ser instrumento para a garantia de uma vida digna a essas mulheres? Como o Direito da Seguridade Social pode contribuir para a redução das desigualdades de gênero e raça em nosso país?

A proposta de um grupo de pesquisa que buscasse responder estas questões enquadrou-se na Resolução CoG E CoCEx n. 4.738, de 22 de fevereiro de 2000, que instituiu a disciplina de "Atividades de Cultura e Extensão" para a graduação da Faculdade de Direito da USP, de caráter optativo, uma vez que dentre as atividades que podem ser cadastradas está prevista a "prática de pesquisa e/ou estágios, desde que estes últimos não sejam definidos como estágios curriculares" (art. 20, alínea “c”). ${ }^{13}$

Nestes termos, foi fundado o Grupo de Pesquisa Direito da Seguridade Social, Gênero e Pobreza, sob orientação do Professor Homero Batista Mateus da Silva, realizando-se seu cadastramento perante a Comissão de Cultura e Extensão da Faculdade de Direito, nos termos do Edital CCEx FD de 21 de outubro de 2013, para início das

10 ORGANIZAÇÃO DAS NAÇÕES UNIDAS. Declaração e Plataforma de Ação da IV Conferência Mundial sobre as Mulheres - Pequim 1995. Disponível em: $<$ http://www.unfpa.org.br/Arquivos/declaracao_beijing. pdf $>$. Acesso em: 10 abr. 2015.

11 Alguns estudos problematizam o uso do termo "feminização da pobreza", mas entendemos sua importância, por ter evidenciado a condição das mulheres pobres no planeta, em especial daquelas que provém sozinhas o sustento da família, reforçando o impacto das políticas de erradicação da pobreza na promoção da igualdade entre os sexos. Para as críticas, ver: MEDEIROS, Marcelo; COSTA, Joana Simões. Is There a Feminization of Poverty in Latin America? World Development, v. 36, n. 1, p. 115-127, 2008; e COSTA, Joana Simões et al. A face feminina da pobreza: sobre-representação e feminização da pobreza no Brasil. Brasília: IPEA, 2005.

12 BRASIL. Relatório Anual Socioeconômico da Mulher. Brasília: Secretaria de Políticas para as Mulheres, 2013. p. 55.

13 Disponível em: <www.direito.usp.br/extensao/resolucaoCoG.CoCEx_4738_2000.pdf> Acesso em: 10 abr. 2015. 
atividades no primeiro semestre de 2014, de modo a receber principalmente estudantes da graduação que haviam cursado a disciplina Seguridade Social (DTB 0317) no semestre anterior.

3. A iniciativa de associar estudos de gênero ao direito da seguridade social

O Grupo de Pesquisa Direito da Seguridade Social, Gênero e Pobreza propõe inserir a perspectiva de gênero nos estudos da Seguridade Social, fundamental para a formação de um olhar sensível à opressão das mulheres no contexto jurídico e de elaboração de políticas públicas nessa área, o que é atualmente incompatível com as limitações da grade curricular do bacharelado da Faculdade de Direito da USP.

Essa iniciativa visa a utilizar o gênero como categoria analítica das normas e políticas no campo da Seguridade Social, de modo a permitir enxergar as dinâmicas de poder que, mesmo dentro de uma conjuntura de igualdade formal de direitos, mantém grandes barreiras para a efetivação da cidadania das mulheres. Essa perspectiva abre espaço para a elaboração de um Direito da Seguridade Social crítico e sensível às demandas específicas que as relações desiguais entre os sexos provocam, levando em conta especialmente a realidade e as demandas das mulheres pobres, maiores afetadas na dinâmica da exclusão social.

Nesse sentido, a Organização Internacional do Trabalho (OIT) temse mostrado preocupada com a abordagem da Seguridade Social voltada às mulheres, reconhecendo que a experiência da pobreza é diferenciada por gênero. A já mencionada Recomendação 202, sobre os pisos de proteção social, determina expressamente a seus membros a aplicação dos princípios da não-discriminação, da igualdade de gênero e da capacidade de resposta a necessidades especiais de cada sexo (item 3). ${ }^{14}$

Tendo como base a referida Recomendação, a publicação da OIT intitulada "Social Protection Floors and gender equality: a brief overview" destaca a garantia do efetivo e equitativo acesso à proteção social como chave para ajudar a alcançar a igualdade de gênero. Nessa linha, afirma que

Social protection schemes, as well as wider social security systems, can contribute to women's economic empowerment and greater gender equality, where they are designed, implemented and monitored in a genderresponsive way. On the other hand, gender-blind schemes

14 ORGANIZAÇÃO INTERNACIONAL DO TRABALHO. Recommendation 202 - Social Protection Floors Recommendation. Geneva: ILO, 2012. 
and systems can perpetuate unequal gender relations and may even exacerbate them in some cases. ${ }^{15}$

Por conseguinte, a importância de unir a perspectiva de gênero ao Direito revela-se na possibilidade de tornar juridicamente visível - e não mais indiferente ao gênero, ou "gender blind" - o papel social atribuído às mulheres em nossa sociedade, por meio da divisão social do trabalho, que historicamente as vincula ao trabalho doméstico e de cuidado da prole no espaço privado, desvalorizado em face ao trabalho produtivo e público atribuído aos homens. ${ }^{16}$

Dentre as consequências dessa realidade de gênero para a Seguridade Social, a primeira que pode ser destacada é a maior dificuldade de acesso das mulheres aos sistemas previdenciários contributivos, que se deve pela junção de dois fatores principais: a maior presença de mulheres em trabalhos informais e precários, sem cobertura previdenciária, como o emprego doméstico e a agricultura; e os encargos domésticos e familiares suportados quase que exclusivamente pelas mulheres, que dificultam a inserção e permanência no mercado de trabalho e, consequentemente, impedem a manutenção das contribuições. Isso as torna a maioria dos beneficiários do Benefício de Prestação Continuada da Assistência Social à Pessoa Idosa. ${ }^{17}$

Em segundo lugar, observa-se que as mulheres recebem, em média, aposentadorias menores do que os homens e constituem a maioria dos beneficiários do piso previdenciário. ${ }^{18}$ Isso é reflexo da discriminação de gênero no mercado de trabalho, que faz com que aquelas trabalhadoras que conseguem manter-se trabalhando fora de casa sofram com marcante desigualdade salarial: dados gerais mostram que em 2011, o rendimento-hora da população ocupada era de $\mathrm{R} \$ 11,10$ entre os homens e de $\mathrm{R} \$$ 9,20 entre as mulheres. ${ }^{19}$ Ademais, estudo da Universidade Federal de Minas Gerais (UFMG) demonstra que "é maior a dependência econômica relativa das mulheres acima de 60 anos destes benefícios e dos rendimentos de outros membros da família em que vivem". ${ }^{20}$

15 TESSIER, Lou et al. Social protection floors and gender equality: a brief overview. Geneva: International Labour Organization, 2013. p. 3.

16 Para melhor compreensão do tema, ver: KERGOAT, Danièle. Divisão sexual do trabalho e relações sociais de sexo. In: HIRATA, Helena; LABORIE, Françoise; LE DOARÉ, Hélène; SENOTIER, Danièle (Org.). Dicionário crítico do feminismo. São Paulo: Editora Unesp, 2009. p. 67-75; e HIRATA, Helena. Nova divisão sexual do trabalho? Um olhar voltado para a empresa e a sociedade. São Paulo: Boitempo, 2002.

17 BRASIL. Anuário Estatístico da Previdencia Social - AEPS 2013. Brasília: Ministério da Previdência Social /DATAPREV, 2013. p. 148.

18 MARRI, Izabel Guimarães; WAJNMAN, Simone; ANDRADE, Mônica Viegas. Reforma da Previdência Social: simulações e impactos sobre os diferenciais de sexo. Revista Brasileira de Estudos de População, Rio de Janeiro, v. 28, n. 1, p. 37-56, jan./jun. 2011.

19 BRASIL. Relatório Anual Socioeconômico da Mulher. Brasília: Secretaria de Políticas para as Mulheres, 2013. p. 48.

20 MARRI, Izabel Guimarães; WAJNMAN, Simone; ANDRADE, Mônica Viegas. Reforma da Previdência Social: simulações e impactos sobre os diferenciais de sexo. Revista Brasileira de Estudos de População, 
Essa realidade é reconhecida na publicação da OIT anteriormente citada, na qual se afirma que "Women's generally lower rates of labour force participation as compared to men, gendered employment patterns, and women's greater representation in the informal economy result in lower rates of social security coverage of women", indicando, em particular, que "women tend to benefit less from coverage of contributory social security schemes, as such schemes are usually linked to formal employment". ${ }^{21}$

A mesma publicação ainda dá destaque à maior expectativa de vida das mulheres, que chegam a ter em média quatro anos mais que os homens, o que implica em contingências relacionadas à idade avançada e ao gênero. Isso porque maior expectativa de vida está relacionada ao aumento de problemas de saúde, perda de rendimentos devido à incapacidade para o trabalho, perda do vigor físico e necessidade de cuidados continuados. "This gives rise to specific social protection needs with regard to effective access to health protection and other social services, as well as income security".22

Assim, atentar à maior expectativa de vida entre as mulheres e à decorrente feminização da velhice pobre permite perceber a necessidade de um olhar específico da Seguridade Social às mulheres idosas. Em termos previdenciários, medidas de inserção das mulheres no regime geral permitirão ao menos sua subsistência na velhice. Pensando na Assistência, é preciso amparar as mulheres que hoje em dia não tem nenhuma fonte de renda para garantir seu sustento na velhice. Ademais, o Sistema Único de Saúde precisa estar pronto para atender as necessidades médicas dos corpos e mentes das mulheres que chegaram à idade avançada sem amparo.

Todas essas perspectivas permitem concluir que

Gender-based inequalities in the labour market and the unequal share of unpaid family responsibilities born by women as well as a subsequent bias in the way social protection systems are structured (mainly through social insurance for the formal economy in many countries) have resulted in unequal access, coverage and provision of social security for women. In return, gender inequalities and the lack of consideration given to women's specific social protection needs often put women at greater risk throughout the life course. This situation calls for a gender responsive policy approach. ${ }^{23}$

Rio de Janeiro, v. 28, n. 1, p. 37-56, jan./jun. 2011.

${ }_{21}$ TESSIER, Lou et al. Social protection floors and gender equality: a brief overview. Geneva: International Labour Organization, 2013. p. 3.

22 TESSIER, Lou et al. Social protection floors and gender equality: a brief overview. Geneva: International Labour Organization, 2013. p. 8.

23 TESSIER, Lou et al. Social protection floors and gender equality: a brief overview. Geneva: International Labour Organization, 2013. p. 9. 


\section{Atividades desenvolvidas em 2014}

Como primeira abordagem para um semestre de estudos do Grupo de Pesquisa, optamos por um recorte em Assistência Social que dialogava com o alvo de grandes debates do cenário nacional daquele período: os programas de transferência de renda governamentais, em especial o Programa Bolsa Família e a titularidade das mulheres. Vale mencionar que 70\% dos domicílios que recebiam Bolsa Família em 2006 eram chefiados por mulheres negras ou homens negros. ${ }^{24}$ Assim, nosso objetivo era desenvolver a reflexão crítica acerca destes programas assistenciais, especialmente enquanto forma de compensação das desigualdades entre homens e mulheres e de combate à pobreza no Brasil.

No primeiro edital, lançado em 07 de fevereiro de 2014, foram abertas vagas para estudantes da graduação que cumprissem os seguintes requisitos: (i) estar regularmente matriculado/a na USP e já ter cursado a disciplina Seguridade Social; (ii) disponibilidade para dedicação de quatro horas semanais às atividades do projeto; (iii) disponibilidade para reuniões presenciais quinzenais, no período noturno, em sala do Departamento de Direito do Trabalho e Seguridade Social.

Foram 14 alunas e alunos selecionados para integrarem o grupo formalmente - seis cursando o $7^{\circ}$ semestre $\left(4^{\circ}\right.$ ano) e oito cursando o $9^{\circ}$ semestre $\left(5^{\circ}\right.$ ano $)$-, além de outras quatro inscrições de ouvintes, dentre os quais um egresso da Faculdade de Direito da USP, dois estudantes da pós-graduação e um profissional de área externa ao Direito.

Os temas a serem estudados nos encontros do primeiro semestre de atividades do grupo de pesquisa foram definidos pensando em dois blocos: o primeiro de formação geral sobre Direito da Seguridade Social e Teoria de Gênero, de forma a dar a base teórica para o estudo do segundo bloco, focado no recorte nos programas de transferência de renda e suas consequências na vida das mulheres beneficiárias.

Desse modo, com bibliografia selecionada e debates conduzidos pelo professor orientador e pela monitora da pós-graduação, Regina Stela Corrêa Vieira, os encontros trataram das seguintes temáticas: (1) Direitos Sociais, Seguridade Social e a

24 INSTITUTO DE PESQUISA ECONÔMICA APLICADA. Retrato das desigualdades de gênero e raça. 4. ed. Brasília: IPEA, 2011. p. 34. 
Constituição de 1988; ${ }^{25}$ (2) Inclusão social, desigualdades regionais e o papel do Estado; ${ }^{26}$ (3) Gênero, Raça e Pobreza: Interseccionalidade;27 (4) Assistência social e o combate à pobreza; ${ }^{28}$ (5) 10 anos de Programa Bolsa Família; ${ }^{29}$ (6) O Programa Bolsa Família e as mulheres: promoção da autonomia ou reafirmação dos papéis de gênero ${ }^{30}$

25 Bibliografia: BERCOVICI, Gilberto; MASSONETTO, Luís Fernando. Os direitos sociais e as constituições democráticas brasileiras: breve ensaio histórico. In: RÚBIO, David Sanchéz; FLORES, Joaquín Herrera; CARVALHO, Salo de (Org.). Direitos humanos e globalização: fundamentos e possibilidades desde a teoria crítica. Rio de Janeiro: Lumen Juris, 2004. p. 505-524; GALDINO, Flávio. Introdução à teoria dos custos dos direitos: direitos não nascem em árvores. Rio de Janeiro: Lumen Juris, 2005. p. 199-214; e MONNERAT, Giselle Lavinas; SOUZA, Rosimary Gonçalves de. Da seguridade social à intersetorialidade: reflexões sobre a integração das políticas sociais no Brasil. Revista Katálysis, Florianópolis, v. 14, n. 1, jan./ jun. 2011. Bibliografia Complementar: VIDAL NETO, Pedro. Princípios da seguridade social. Revista de Previdência Social, São Paulo, v. 19, n. 171, p. 106-111, fev. 1995.

26 Bibliografia: BERCOVICI, Gilberto. Desigualdades regionais, Estado e Constituição. São Paulo: Max Limonad, 2003. p. 35-67; CASTEL, Robert. As metamorfoses da questão social: uma crônica do salário. Rio de Janeiro: Vozes, 1998. p. 495-537; e POCHMANN, Marcio et al. (Org.) Atlas da exclusão social: agenda não liberal da inclusão social no Brasil. São Paulo: Cortez, 2005. v. 5. p. 67, 97-109. Bibliografia Complementar: LICIO, Elaine Cristina; MESQUITA, Camile Sahb; CURRALERO, Claudia Regina Baddini. Desafios para a coordenação intergovernamental do Programa Bolsa Família. Revista administração de empresas, v. 51, n. 5, p. 458-470, set./out. 2011.

27 Bibliografia: HIRATA, Helena; KERGOAT, Danièle. Novas configurações da divisão sexual do trabalho. Cadernos de Pesquisa, v. 37, n. 132, p. 595-609, set./dez. 2007; KERGOAT, Danièle. Dinâmica e consubstancialidade das relações sociais. Novos Estudos: CEBRAP, n. 86, p. 93-103, 2010. Disponível em: $<$ http://novosestudos.uol.com.br/v1/files/uploads/contents/146/20100407_06_NEC86_kergoat_p92a103. pdf>; e SOARES, Vera. Políticas Públicas para igualdade: o papel do Estado e diretrizes. In: GODINHO, Tatau; SILVEIRA, Maria Lucia da. Politicas públicas e igualdade de gênero. São Paulo: Coordenadoria Especial da Mulher da Prefeitura de São Paulo, 2004. p. 113-126. Bibliografia Complementar: PENIDO, Lais de Oliveira. A igualdade dos gêneros nas relações de trabalho. Brasília: ESMPU, 2006.

28 Bibliografia: FAGNANI, Eduardo. Seguridade Social: a experiência brasileira e o debate internacional. Análises e propostas, São Paulo, n. 42, dez. 2011; e REGO, Walquiria Domingues; PINZANI, Alessandro. Vozes do bolsa família: autonomia, dinheiro e cidadania. São Paulo: Editora Unesp, 2013. p. 147-153, 171 188. Bibliografia Complementar: ORGANIZAÇÃO INTERNACIONAL DO TRABALHO. Convenção $n$. 102. Genebra: OIT, 1952. Disponível em: <http://www.oitbrasil.org.br/node/468>.

29 Bibliografia: BICHIR, Renata Mirandola. O Bolsa Família na berlinda? Novos estudos - Cebrap [online], n. 87, p. 115-129, jul. 2010; BRITTO, Tatiana; MEDEIROS, Marcelo; SOARES, Fábio. Transferência de renda no Brasil. Novos estudos - Cebrap [online], n. 79, p. 5-21, nov. 2007.; e PAIVA, Luis Henrique; FALCÃO, Tiago; BARTHOLO, Letícia. Do bolsa família ao Brasil Sem Miséria: um resumo do percurso brasileiro recente na busca da superação da pobreza extrema. In: CAMPELLO, Tereza; NERI, Marcelo Côrtes (Org.). Programa Bolsa Família: uma década de inclusão e cidadania. Brasília: IPEA, 2013. p. 2546.

30 Bibliografia: SORJ, Bila; FONTES, Adriana. Políticas públicas e a articulação entre trabalho e família: comparações inter-regionais. In: FARIA, Nalu; MORENO, Renata (Org.). Cuidado, trabalho e autonomia das mulheres. Coleção Cadernos Sempreviva. São Paulo: SOF, 2010. p. 57-74.; LAVINAS, Lena; COBO, Barbara; VEIGA, Alinne. Bolsa Família: Impacto das transferências de renda sobre a autonomia das mulheres e as relações de gênero. Revista Latinoamericana de Población, v. 6, n. 10, p. 31-54, 2012; e MARIANO, Silvana Aparecida; CARLOTO, Cássia Maria. Gênero e combate à pobreza. Revista Estudos Feministas, Florianópolis, v. 17, n. 3, p. 901-908, set./dez.2009. Bibliografia Complementar: REGO, Walquiria Leão. Aspectos teóricos das políticas de cidadania: uma aproximação ao Bolsa Família. Lua Nova, São Paulo, v. 73, p. 147-185, 2008. 
No primeiro encontro, o texto dos professores Gilberto Bercovici e Luís Fernando Massonetto introduziu a compreensão histórica das conquistas de direitos sociais ao longo das Constituições democráticas brasileiras, desde 1934 até 1988, refutando os críticos do Estado Social e demonstrando a perspectiva de que o desenvolvimento econômico está atrelado à distribuição de renda. ${ }^{31}$ Partindo desta perspectiva, foi debatida a visão de "custos" dos direitos de Flávio Galdino. ${ }^{32}$ Além disso, o artigo de Giselle Lavinas Monnerat e Rosimary Gonçalves de Souza trouxe a percepção de que a articulação do sistema de Seguridade Social prevista na Constituição ainda não foi implantado, gerando a necessidade de integração entre as políticas sociais nas áreas da saúde, previdência e assistência. $^{33}$

O segundo encontro foi dedicado aos debates sobre o papel do Estado na inclusão social e diminuição das desigualdades regionais do país. Para isso, trechos do livro "Desigualdades regionais, Estado e Constituição" do professor Gilberto Bercovici, que traz o desafio furtadiano e a diferenciação entre modernização e o real desenvolvimento de uma nação, ${ }^{34}$ foram analisados em conjunto com dados sobre desigualdades regionais trazidos no volume 5 do "Atlas da exclusão social", que demonstram "quão disforme geograficamente ainda é o Brasil em termos de inclusão social". ${ }^{35}$ A esta perspectiva nacional foi somado o Capítulo VIII de "As metamorfoses da questão Social”, de Robert Castel, no qual trata-se da questão dos supranumerários, ou seja, aquelas pessoas que nos atuais moldes do sistema capitalista não são integrados, tampouco integráveis na sociedade. ${ }^{36}$

No terceiro encontro foram introduzidos pontos centrais da teoria de gênero, a fim de estabelecer uma perspectiva embasada acerca da condição das mulheres em nossa sociedade e de sua maior vulnerabilidade em relação à pobreza. Desse modo, o texto de Helena Hirata e Danièle Kergoat elucida que as relações de poder entre os sexos são sustentadas por uma base material - o trabalho -, e que apesar de a divisão

31 BERCOVICI, Gilberto; MASSONETTO, Luís Fernando. Os Direitos Sociais e as Constituições Democráticas Brasileiras: Breve Ensaio Histórico. In: RÚBIO, David Sanchéz; FLORES, Joaquín Herrera; CARVALHO, Salo de (Org.). Direitos humanos e globalização: fundamentos e possibilidades desde a teoria crítica. Rio de Janeiro: Lumen Juris, 2004. p. 505-524.

32 GALDINO, Flávio. Introdução à teoria dos custos dos direitos: direitos não nascem em árvores. Rio de Janeiro: Lumen Juris, 2005. p. 199-202.

33 MONNERAT, Giselle Lavinas; SOUZA, Rosimary Gonçalves de. Da seguridade social à intersetorialidade: reflexões sobre a integração das políticas sociais no Brasil. Revista Katálysis, Florianópolis, v. 14, n. 1, jan./ jun. 2011.

34 BERCOVICI, Gilberto. Desigualdades regionais, Estado e Constituição. São Paulo, Max Limonad, 2003. p. 35-67.

35 POCHMANN, Marcio et al. (Org.). Atlas da exclusão social: agenda não liberal da inclusão social no Brasil. São Paulo: Cortez, 2005. v. 5, p. 67, 97-109.

36 CASTEL, Robert. As metamorfoses da questão social: uma crônica do salário. Rio de Janeiro: Vozes, 1998. p. 495-537. 
sexual do trabalho ter tomado novas formas da atualidade, as desigualdades permanecem sistêmicas. ${ }^{37} \mathrm{O}$ artigo sobre consubstancialidade de Danièle Kergoat traz a perspectiva de que as dimensões gênero, raça e classe são coextensivas. ${ }^{38}$ Por fim, o texto de Vera Soares traz a necessidade de integração e articulação das políticas públicas de igualdade, para que elas não remedeiem apenas um aspecto da vida das pessoas, mas mudem sua realidade de maneira estrutural. ${ }^{39}$

Formada a base teórica de nossos estudos, os encontros seguintes passaram a abordar de maneira mais direta a Assistência Social, os programas de transferência de renda e a titularidade das mulheres. Assim, o quarto encontro trouxe trechos do livro "Vozes do Bolsa Família", de Walquiria Domingues Rego e Alessandro Pinzani, no qual os autores afirmam que o Programa Bolsa Família garante o direito à vida de milhões de brasileiros e brasileiras, mas não resolve o problema da pobreza. ${ }^{40} \mathrm{~A}$ estes trechos somou-se a percepção de Eduardo Fagnani, de que os programas de transferência de renda são apenas uma parte do sistema de Seguridade Social, não podendo ser um fim em si mesmos. ${ }^{41}$

Para o quinto encontro, textos com diferentes pontos de vista sobre o Programa Bolsa Família foram selecionados, fazendo o balanço de sua aplicação ao longo de dez anos e de seus resultados. Assim, o artigo de Renata Mirandola Bichir reconhece avanços no combate à pobreza, mas aponta a necessidade de articulação dos programas em esfera federal e das iniciativas estaduais e municipais, bem como de criação "portas de saída" para os beneficiários. ${ }^{42} \mathrm{O}$ estudo de Tatiana Britto, Marcelo Medeiros e Fábio Soares afirma que os impactos do programa sobre a pobreza são visíveis e demonstra que não há comprovação de que a transferência de renda impacte a participação dos beneficiários no mercado de trabalho. ${ }^{43}$ Já o texto de Luis Henrique Paiva, Tiago Falcão e Leticia Bartholo traz a evolução dos programas de transferência condicionada de renda,

37 HIRATA, Helena; KERGOAT, Danièle. Novas Configurações da Divisão Sexual do Trabalho. Cadernos de Pesquisa, v. 37, n. 132, p. 595-609, set./dez. 2007.

38 KERGOAT, Danièle. Dinâmica e consubstancialidade das relações sociais. Novos estudos - Cebrap [online], n. 86, p. 93-103, mar. 2010.

39 SOARES, Vera. Políticas Públicas para igualdade: o papel do Estado e diretrizes. In: GODINHO, Tatau; SILVEIRA, Maria Lucia da. Políticas públicas e igualdade de gênero. São Paulo: Coordenadoria Especial da Mulher da Prefeitura de São Paulo, 2004. p. 113-126.

40 REGO, Walquiria Domingues; PINZANI, Alessandro. Vozes do bolsa família: Autonomia, Dinheiro e Cidadania. São Paulo: Editora Unesp, 2013. p. 147-153, 171- 188.

${ }^{41}$ FAGNANI, Eduardo. Seguridade social: a experiência brasileira e o debate internacional. Análises e propostas, n. 42. São Paulo: Friedrich Ebert Stiftung, 2011.

42 BICHIR, Renata Mirandola. O Bolsa Família na berlinda? Novos estudos - Cebrap [online], n. 87, p. 115129, jul. 2010.

43 BRITTO, Tatiana; MEDEIROS, Marcelo; SOARES, Fábio. Transferência de renda no Brasil. Novos estudos - Cebrap [online], n. 79, p. 5-21, nov. 2007. 
falando sobre a implantação do Cadastro Único para Programas Sociais - CadÚnico e sobre o Plano Brasil sem Miséria. ${ }^{44}$

Por fim, no sexto encontro, chegamos aos debates acerca da centralidade das mulheres no Programa Bolsa Família, por serem elas as beneficiárias preferenciais, o que lhes dá controle da economia doméstica ao mesmo tempo em que as responsabiliza pelo cumprimento de suas condicionalidades. Bila Sorj e Adriana Fontes criticam o programa por transferir renda para as mulheres desempenharem o seu papel "tradicional" dentro da família, concluindo que o desafio a ser superado pelas políticas públicas é conciliar o combate à pobreza com a promoção da autonomia das mulheres, de modo a incentivar a participação das beneficiárias no mercado de trabalho. ${ }^{45}$

No mesmo sentido, Lena Lavinas, Barbara Cobo e Alinne Veiga demonstram que a renda não é suficiente para operar o empoderamento das mulheres, pois é necessário que se criem meios de desobrigar as mulheres de suas funções domésticas e reprodutivas, mas apontam que as beneficiárias, ao não quererem mais filhos, demonstram a vontade de modificar seu lugar nas relações de gênero. ${ }^{46}$ De forma semelhante, Silvana Aparecida Mariano e Cássia Maria Carloto, ao analisarem a atuação do Programa Bolsa Família em Londrina, entendem que ele cria mecanismos que minimizam a responsabilidade dos homens e responsabilizam as mulheres com o cuidado das crianças, o que contribui para a cristalização dos papéis de gênero. ${ }^{47}$

Além da relatoria dos textos e do levantamento de questões para o debate acadêmico durante os encontros, cada integrante do grupo de pesquisa também deveria fazer a busca e seleção de artigos acadêmicos referentes ao Direito da Seguridade Social que abordem questões de gênero e/ou pobreza, para elaboração de um ensaio sobre o modo como a doutrina aborda nosso objeto de pesquisa, a fim de demonstrarem sua capacidade de leitura crítica e compreensão dos debates do semestre. O resultado dos ensaios demonstrou o engajamento e sensibilização de todos e todas aos estudos desenvolvidos.

Assim, o primeiro semestre de vida do grupo de pesquisa demonstrou a pertinência do incentivo à pesquisa universitária, que favorece a troca de conhecimento

44 PAIVA, Luis Henrique; FALCÃO, Tiago; BARTHOLO, Letícia. Do Bolsa Família ao Brasil Sem Miséria: um resumo do percurso brasileiro recente na busca da superação da pobreza extrema. In: CAMPELLO, Tereza; NERI, Marcelo Côrtes (Org.). Programa Bolsa Família: uma década de inclusão e cidadania. Brasília: IPEA, 2013. p. 25-46.

45 SORJ, Bila; FONTES, Adriana. Políticas públicas e a articulação entre trabalho e família: comparações inter-regionais. In: FARIA, Nalu; MORENO, Renata (Org.). Cuidado, trabalho e autonomia das mulheres. São Paulo: SOF, 2010. (Coleção Cadernos Sempreviva). p. 57-74.

46 LAVINAS, Lena; COBO, Barbara; VEIGA, Alinne. Bolsa Família: Impacto das transferências de renda sobre a autonomia das mulheres e as relações de gênero. Revista Latinoamericana de Población, v. 6, n. 10, p. 31-54, 2012.

47 MARIANO, Silvana Aparecida; CARLOTO, Cássia Maria. Gênero e combate à pobreza. Revista Estudos Feministas, Florianópolis, v. 17, n. 3, p. 901-908, set./dez.2009. 
entre estudantes de graduação, de pós-graduação e professores, abre horizontes e permite estudos interdisciplinares, enriquecendo a visão de pesquisadores do Direito com outros enfoques, como das Ciências Sociais, da Economia e da Gestão de Políticas Públicas, essencial para que a Universidade forme não apenas profissionais capazes de compreender as demandas de um mundo cada vez mais complexo, mas seres humanos sensibilizados com as questões sociais do país.

\section{Considerações finais}

Diante da experiência piloto bem-sucedida, o Grupo de Pesquisa Direito da Seguridade Social, Gênero e Pobreza objetiva ser permanente, sendo oferecido todo primeiro semestre de cada ano letivo, em alternância com a oferta da disciplina Seguridade Social (DTB0317). Satisfeitos com os primeiros resultados, decidimos avançar nossos estudos em 2015, tendo como base novos eixos temáticos: (1) estudo crítico da Seguridade Social; (2) Previdência Social e a aposentadoria por idade de homens e mulheres; e (3) Saúde e o parto humanizado no SUS.

Por meio de seus objetos de estudo, o Grupo de Pesquisa Direito da Seguridade Social, Gênero e Pobreza tem como finalidade instalar na Faculdade de Direito da USP a cultura política da reflexão permanente e dirigida para as grandes questões da Seguridade Social, de relevância nacional, estimulando a pesquisa e o pensamento crítico nesta área do conhecimento, de modo a corresponder aos investimentos sociais aportados à Universidade Pública, fomentando a elaboração de base teórica para a construção de uma sociedade mais justa e igualitária.

São Paulo, abril de 2015.

\section{Referências}

BERCOVICI, Gilberto. Desigualdades regionais, Estado e Constituição. São Paulo: Max Limonad, 2003.

BERCOVICI, Gilberto; MASSONETTO, Luís Fernando. Os direitos sociais e as constituições democráticas brasileiras: breve ensaio histórico. In: RÚBIO, David Sanchéz; FLORES, Joaquín Herrera; CARVALHO, Salo de (Org.). Direitos humanos e globalização: fundamentos e possibilidades desde a teoria crítica. Rio de Janeiro: Lumen Juris, 2004. p. 505-524.

BICHIR, Renata Mirandola. O Bolsa Família na berlinda? Os desafios atuais dos programas de transferência de renda. Novos estudos: Cebrap, n. 87, p. 115-129, jul. 2010. Disponível em: <http:// novosestudos.uol.com.br/v1/files/uploads/contents/148/20100816_06_Mirandola_87_114a129. pdf $>$. 
BRASIL. Anuário Estatístico da Previdência Social - AEPS 2013. Brasília: Ministério da Previdência Social /DATAPREV, 2013.

. Relatório Anual Socioeconômico da Mulher. Brasília: Secretaria de Políticas para as Mulheres, 2013.

BRITTO, Tatiana; MEDEIROS, Marcelo; SOARES, Fábio. Transferência de renda no Brasil. Novos Estudos: Cebrap, n. 79, p. 5-21, nov. 2007. Disponível em: <http://novosestudos.uol.com.br/ v1/files/uploads/contents/39/20080622_01_Bolsa.pdf>.

CASTEL, Robert. As metamorfoses da questão social: uma crônica do salário. Rio de Janeiro: Vozes, 1998. p. 495-537.

COSTA, Joana Simões. et al. A face feminina da pobreza: sobre-representação e feminização da pobreza no Brasil. Brasília: IPEA, 2005.

DIÁRIO OFICIAL DO ESTADO DE SÃO PAULO. Poder Executivo - Seção 1, 08.out.2015, p. 69. Disponível em: <http://www.imprensaoficial.com.br/PortalIO/DO/ BuscaDO2001Documento_11_4. aspx?link=/2005/executivo\%2520secao\%2520i/outubro/08/pag_ 0069_47S5K48D78MHJe2LUG18H3IVPPH.pdf\&pagina=69\&data=08/10/2005\&caderno=Execut ivo\%20I\&paginaordenacao=10069>. Acesso em: 25 abr. 2015.

FAGNANI, Eduardo. Seguridade Social: a experiência brasileira e o debate internacional. Análises e Propostas, São Paulo, n. 42, dez. 2011.

GALDINO, Flávio. Introdução à teoria dos custos dos direitos: direitos não nascem em árvores. Rio de Janeiro: Lumen Juris, 2005.

HIRATA, Helena. Nova divisão sexual do trabalho? Um olhar voltado para a empresa e a sociedade. São Paulo: Boitempo, 2002.

HIRATA, Helena; KERGOAT, Danièle. Novas configurações da divisão sexual do trabalho. Cadernos de Pesquisa, São Paulo, v. 37, n. 132, p. 595-609, set./dez. 2007.

INSTITUTO DE PESQUISA ECONÔMICA APLICADA. Retrato das desigualdades de gênero e raça. 4. ed. Brasília: IPEA, 2011.

KERGOAT, Danièle. Dinâmica e consubstancialidade das relações sociais. Novos Estudos: CEBRAP, n. 86, p. 93-103, 2010. Disponível em: < http://novosestudos.uol.com.br/v1/files/uploads/ contents/146/20100407_06_NEC86_kergoat_p92a103.pdf $>$.

Divisão sexual do trabalho e relações sociais de sexo. In: HIRATA, Helena; LABORIE, Françoise; LE DOARÉ, Hélène; SENOTIER, Danièle (Org.). Dicionário crítico do feminismo. São Paulo: Editora Unesp, 2009. p. 67-75.

KERNER, Ina. Tudo é interseccional? Sobre a relação entre racismo e sexismo. Novos Estudos: CEBRAP, n. 93, p. 45-58, 2012. Disponível em: <http://novosestudos.uol.com.br/v1/files/uploads/ contents/content_25/file_25.pdf $>$. 
LAVINAS, Lena; COBO, Barbara; VEIGA, Alinne. Bolsa família: impacto das transferências de renda sobre a autonomia das mulheres e as relações de gênero. Revista Latinoamericana de Población, Montevideo, v. 6, n. 10, p. 31-54, 2012.

LICIO, Elaine Cristina; MESQUITA, Camile Sahb; CURRALERO, Claudia Regina Baddini. Desafios para a coordenação intergovernamental do Programa Bolsa Família. Revista Administração de Empresas, São Paulo, v. 51, n. 5, p. 458-470, set./out. 2011.

MARIANO, Silvana Aparecida; CARLOTO, Cássia Maria. Gênero e combate à pobreza. Revista Estudos Feministas, Florianópolis, v. 17, n. 3, p. 901-908, set./dez. 2009.

MARRI, Izabel Guimarães; WAJNMAN, Simone; ANDRADE, Mônica Viegas. Reforma da Previdência Social: simulações e impactos sobre os diferenciais de sexo. Revista Brasileira de Estudos de População, Rio de Janeiro, v. 28, n. 1, p. 37-56, jan./jun. 2011.

MEDEIROS, Marcelo; COSTA, Joana Simões. Is There a Feminization of Poverty in Latin America? World Development, v. 36, n. 1, p. 115-127, 2008.

MONNERAT, Giselle Lavinas; SOUZA, Rosimary Gonçalves de. Da seguridade social à intersetorialidade: reflexões sobre a integração das políticas sociais no Brasil. Revista Katálysis, Florianópolis, v. 14, n. 1, jan./jun. 2011.

ORGANIZAÇÃO DAS NAÇÕES UNIDAS. Declaração e plataforma de ação da IV Conferência Mundial sobre as Mulheres - Pequim 1995. Disponível em: <http:/www.unfpa.org.br/ Arquivos/ declaracao_beijing.pdf>. Acesso em: 10 abr. 2015.

. Declaração Universal dos Direitos Humanos. Nova Iorque: ONU, 1948. Disponível em: $<$ http://www.dudh.org.br/wp-content/uploads/2014/12/dudh.pdf $>$. Acesso em: 07 abr. 2015.

ORGANIZAÇÃO INTERNACIONAL DO TRABALHO. Recommendation 202: Social Protection Floors Recommendation. Geneva: ILO, 2012.

. Recommendation 202: Social protection floors recommendation. Geneva: ILO, 2012. Disponível em: <http://www.ilo.org/dyn/normlex/en/f?p=NORMLEXPUB:12100:0::NO::P12100_ INSTRUMENT_ID:3065524> Acesso em: 07 abr. 2015.

PAIVA, Luis Henrique; FALCÃO, Tiago; BARTHOLO, Letícia. Do Bolsa Família ao Brasil sem Miséria: um resumo do percurso brasileiro recente na busca da superação da pobreza extrema. In: CAMPELLO, Tereza; NERI, Marcelo Côrtes (Org.). Programa bolsa família: uma década de inclusão e cidadania. Brasília: IPEA, 2013. p. 25-46.

PENIDO, Lais de Oliveira. A igualdade dos gêneros nas relações de trabalho. Brasília: ESMPU, 2006.

POCHMANN, Marcio et al. (Org.) Atlas da exclusão social: agenda não liberal da inclusão social no Brasil. São Paulo: Cortez, 2005. v. 5. 
REGO, Walquiria Leão; PINZANI, Alessandro. Vozes do Bolsa Família: autonomia, dinheiro e cidadania. São Paulo: Editora Unesp, 2013.

REGO, Walquiria Leão. Aspectos teóricos das políticas de cidadania: uma aproximação ao bolsa família. Lua Nova, São Paulo, v. 73, p. 147-185, 2008.

SOARES, Vera. Políticas Públicas para igualdade: o papel do Estado e diretrizes. In: GODINHO, Tatau; SILVEIRA, Maria Lucia da. Políticas públicas e igualdade de gênero. São Paulo: Coordenadoria Especial da Mulher da Prefeitura de São Paulo, 2004. p. 113-126.

SORJ, Bila; FONTES, Adriana. Políticas públicas e a articulação entre trabalho e família: comparações inter-regionais. In: FARIA, Nalu; MORENO, Renata (Org.). Cuidado, trabalho e autonomia das mulheres. São Paulo: SOF, 2010. p. 57-74. (Coleção Cadernos Sempreviva).

TESSIER, Lou. et al. Social protection floors and gender equality: a brief overview. Geneva: International Labour Organization, 2013.

UNIVERSIDADE DE SÃO PAULO. Ata da $154^{a}$ Sessão da Congregação. Acervo da Assistência Acadêmica, 28. jun. 2001.

. Ofício DTB-0242001/FD/1904. Acervo do Departamento de Direito do Trabalho e da Seguridade Social, 2001.

VIDAL NETO, Pedro. Princípios da seguridade social. Revista de Previdência Social, São Paulo, v. 19, n. 171, p. 106-111, fev. 1995. 